\title{
Violación del derecho a la defensa de las personas y el debido proceso en los juicios de jurisdicción coactiva en el art. 968 del código de procedimiento civil.
}

Violation of the right to the defense of the people and the due process in the court jurisdiction judges in the art. 968 of the code of civil procedure.

Andrés Gustavo Loza Torres. ${ }^{1}$, Raquel Virginia Colcha Ortiz. ${ }^{2}$, Katherin Alejandra Carrera Silva. ${ }^{3} \&$ María Del Carmen Moreno Albuja. ${ }^{4}$

DOI: https://doi.org/10.33262/visionariodigital.v3i3.668

\begin{abstract}
.
The present research has as its primary objective, a study and legal analysis about what our country is the fulfillment of the constitutional right to defend people and due process in the trials of jurisdiction of coercive, procedure legal parameters that must be respected, exceptions to this process, the failure of constitutional rights and the importance of such judgments in our society. This topic has been of vital importance because of the events of recent years in our country, as the Ecuadorian State has taken over public agencies thereof, as mentioned at the BNF, branch Alausí fundamental research body causing this, that natural or legal persons with outstanding items to this body, no longer have purely civil debt recoverable by executive action, but putting them in the plight of the coercive judgment. In the proposed research work will focus on determining whether the coercive trial violates constitutional rights and guarantees in order to establish whether the effective protection and legal certainty are being respected in each of the processes. In analyzing each of coercive processes in the BNF, branch Alausí in liquidation effectiveness in recovering overdue loans by the competent authority and the impact of this on society will be established. Will also be established if the coercive jurisdiction has the same guarantees as the ordinary courts, or whether the fact that the state that drives the trial has privileges and benefits which do not enjoy any other natural or legal person that drives trial ordinary processes.
\end{abstract}

\footnotetext{
${ }^{1}$ Escuela Superior Politécnica de Chimborazo, Chimborazo Ecuador, andres.loza@espoch.edu.ec

${ }^{2}$ Escuela Superior Politécnica de Chimborazo, Chimborazo Ecuador, raquel.colcha@espoch.edu.ec

${ }^{3}$ Escuela Superior Politécnica de Chimborazo, Chimborazo Ecuador, katherin.carrera@espoch.edu.ec

${ }^{4}$ Escuela Superior Politécnica de Chimborazo, Chimborazo Ecuador ,carmen.moreno@espoch.edu.ec
} 
Keywords: Coercion, Jurisdiction, Processes, Judgments.

\section{Resumen.}

El presente trabajo de investigación, tiene como objetivo primordial, realizar un estudio y análisis jurídico acerca de lo que en nuestro país es el cumplimiento del derecho constitucional a la defensa de las personas y el debido proceso en los juicios de jurisdicción de coactivas, su procedimiento legal, parámetros que deben ser respetados, excepciones a este proceso, la inobservancia a los derechos constitucionales y a la importancia de dichos juicios dentro de nuestra sociedad. Este tema ha sido de vital trascendencia debido a los sucesos ocurridos en los últimos años dentro de nuestro país, ya que el Estado Ecuatoriano ha tomado a su cargo a organismos públicos del mismo, tal como menciona al BNF, sucursal Alausí como ente fundamental de investigación, provocando con esto, que las personas naturales o jurídicas que adeudaban rubros a este organismo, ya no tengan deudas meramente civiles, recuperables por juicio ejecutivo, sino poniéndoles en la difícil situación del juicio coactivo. Dentro del trabajo de investigación propuesto, enfocaré en determinar si el juicio coactivo viola derechos y garantías constitucionales, a fin de establecer si la tutela efectiva y la seguridad jurídica están siendo respetadas en cada uno de los procesos. Al analizar cada uno de los procesos coactivos en el BNF, sucursal Alausí en liquidación se establecerá la eficacia en la recuperación de cartera vencida por parte del organismo competente y el impacto de este en la sociedad. También se establecerá si la jurisdicción coactiva tiene las mismas garantías que la justicia ordinaria, o si por el hecho de ser el Estado el que impulsa el juicio tenga privilegios y beneficios de los cuales no goza ninguna otra persona natural o jurídica que impulse el juicio en los procesos ordinarios.

Palabras Claves: coactiva, jurisdicción, procesos, juicios.

\section{Introducción.}

Este trabajo de investigación pone énfasis en la conexión que existe entre la actuación coactiva de la Administración Tributaria y el respeto a uno de los Derechos Fundamentales de la Persona, como es el derecho que tiene el deudor tributario a que se observe un debido proceso en el ámbito del procedimiento de cobranza coactiva.

Desde una perspectiva constitucional, pretendemos despertar la atención que merece la actuación coactiva de la Administración Tributaria, y la preocupación que dicha actuación genera por el olvido de las formas democráticas, pues, la Administración Tributaria como todas las instituciones es una entidad sometida a la Constitución, cuya normatividad y principios rectores deben ser acatados por la referida Administración. Así, la Administración Tributaria debe respetar la institucionalidad democrática y sus formas, 
como el debido proceso, que no se cumple en el procedimiento de cobranza coactiva, en detrimento de los Derechos Humanos.

\section{Marco Teórico.}

El universo de la investigación está constituido por las siguientes muestras: En los diferentes procesos de jurisdicción coactiva, facultad conferida a través de la Ley a los organismos públicos del Estado para cobrar acreencias, sin recurrir a la jurisdicción ordinaria, aunque la presentación de excepciones por parte de los demandados y las tercerías son de competencia ordinaria.

Ahora bien, el Estado con la finalidad de contar con una vía rápida y eficaz para el cobro de tributos, multas de naturaleza tributaria e intereses (y otras acreencias derivadas de relaciones de Derecho Público) a diferencia del proceso judicial ordinario, ha creado un procedimiento sumarísimo, sencillo en su estructura, conformado por normas procesales de ejecución inmediata, y denominado procedimiento de cobranza coactiva o ejecución coactiva, por medio del cual se obliga a los contribuyentes al pago de la deuda de inmediato y sin discusión alguna, aunque ésta -la deuda u obligación-, no esté acreditada plenamente.

La consideración de la defensa como derecho fundamental conlleva su directa aplicabilidad, el deber de respeto y promoción de las condiciones para el óptimo ejercicio de este derecho por parte de los poderes públicos. Como ya hemos visto el derecho de defensa consiste en un catálogo de derechos instrumentales de rango constitucional recogidos en su mayoría en el art.76 Constitución de la República del Ecuador.

El debido proceso está constituido por la forma de asegurar la objetividad en la confrontación de las pretensiones judiciales, en garantizar el equilibrio armónico de las partes entre sí, bajo la dirección de un tercero imparcial que está dispuesto a dar el derecho a quien le corresponde en virtud de las pruebas. En otras palabras, es el derecho a un proceso justo, donde no haya negación o quebrantamiento de lo que toda persona tiene asignado. En el Derecho Constitucional, al hablar de los elementos constitutivos del Estado Ecuatoriano nos referimos a una característica esencial como es el Estado de Derechos, la norma constitucional establece los derechos de protección y la tutela efectiva de los derechos, especialmente la defensa así como las garantías básicas al debido proceso en cualquier instancia del mismo.

Por otra parte, la jurisdicción coactiva establecida en el código adjetivo civil tipifica la presentación de excepciones para proponer la defensa en el proceso, esto significa consignar el monto de lo adeudado sin eso signifique el pago de la deuda. La sola inobservancia de la constitución conculca los principios constitucionales del Art. 75 y 76 del debido proceso, vulnerando su derecho a la defensa por falta de aplicación del derecho, el mismo que genera una gran afección al patrimonio de los ciudadanos. Uno de los graves problemas que encontramos en materia civil y en el Código de Comercio, es 
cuando el PRINCIPIO DEL DEBIDO PROCESO, se torna inaplicable el derecho a la defensa en los procedimientos de Coactiva, contemplado en el Código de Procedimiento Civil, en el Art. 968".

No se admitirán las excepciones del deudor, sus herederos o fiadores, contra el proceso coactivo, sino después de consignada la cantidad a que asciende la deuda, sus intereses y costas.

Se producen de este modo dos procedimientos similares con situaciones absolutamente contrapuestas; pues, mientras en el campo civil (obligaciones no tributarias) rige el PRINCIPIO SOLVE ET REPETE, es decir, o pagas o se remata, contrariamente en lo tributario (EN LAS OBLIGACIONES TRIBUTARIAS), no rige desde que el Código Fiscal dictado por el Decreto Ley de Emergencia, publicado en el registro Oficial $N^{\circ} 490$, del 25 de junio de 1993, admitió en la coactiva el procedimiento de excepciones y de impugnación, que se repite en el actual Código Tributario, constituyéndose el Código de Procedimiento Civil en norma supletoria.

El juicio de coactiva es una herramienta que las instituciones que brindan un servicio público utilizan para obligar al ciudadano que lo recibe a cumplir con el pago respectivo, si es que este es renuente a cancelar los valores por un consumo determinado. El 20 de octubre del año 2008 el marco jurídico de nuestro país cambió totalmente, al entrar en vigencia una nueva Constitución.

El Art. 167 de la Constitución señala que la potestad de administrar justicia se ejerce por los órganos de la Función Judicial y por los demás órganos y funciones establecidos por la Constitución. La potestad de administrar justicia es de exclusiva competencia de la Función Judicial, por lo tanto nadie que no pertenezca a ella, o a los órganos constituciones, lo puede hacer. Los mal llamados jueces lo violan flagrantemente, ya que incumplen varios de estos enunciados, ellos no pueden ser independientes porque se deben a la institución que demanda, no pueden ser imparciales porque cobran un porcentaje de lo que recauden, y no son competentes porque la competencia nace de la Constitución.

El numeral tres (3) del Art. 168 es contundente al determinar que ninguna autoridad de las demás funciones del Estado podrá desempeñar funciones de administración de justicia ordinaria, invocando el principio de la unidad jurisdiccional. El Dr. Sharman define el principio de imparcialidad como la ausencia de prejuicios frente a un litigio, es decir la ausencia de intereses en que el conflicto se solucione de determinada forma.

\section{Antecedentes.}

Al hacer un análisis de los orígenes del derecho fiscal para la recaudación del fisco es necesario empezar indicando que el origen del procedimiento coactivo nace con las obligaciones de las personas con el Estado, en la antiguiedad estas obligaciones aparecen debido a los impuestos que el Estado los imponía. Desde los inicios de la sociedad, los 
soberanos aplicaban los impuestos en forma de tributos, de los cuales muchos eran reservados para para las clases dominantes y asuntos ceremoniales. La defraudación de impuestos era poco común debido al control directo de recaudación que hacían sacerdotes y soberanos. Todas las comunidades antiguas, tenían alguna forma de tributo.

En la antigüedad, la manera de pagar y cobrar tributos no era equitativa, satisfacía situaciones de capricho, mandato divino o sojuzgamiento de un pueblo por otro. Asimismo, los seres humanos eran parte de los tributos siendo destinados a sacrificios ceremoniales y forzados a efectuar trabajos físicos. "Varias declaraciones de impuestos eran humillantes, ya que el contribuyente tenía que arrodillarse y pedir gracia".

De la historia de nuestro país y en general de América se puede decir que la cultura tributaria llego de la misma forma, es decir a través de las conquistas de los europeos, y posterior a esta la imposición de mitas, obrajes, encomiendas, etc., lo que no cambio con las revoluciones si no que se mantuvieron los tributos para impulsar las revoluciones y después con el desarrollo del nuevo régimen, para mantener al Estado naciente.

En la historia del Ecuador encontramos que en la Constitución de 1812, llamada también Quiteña, la cual fue emitida antes de que seamos república, al referirse a la potestad tributaria en su artículo 35 decía "Es peculiar y privativo de este poder el arreglar toda especie de tasas, contribuciones o derechos que deban exigirse, tanto en la cantidad como en el monto de su recaudación y personas que deban exhibir con atención a las necesidades del estado y a la posibilidad de los contribuyentes.

Sin consentimiento y permiso de la legislatura, ningún particular, ni corporación podrán en lo sucesivo imponer o exigir contribución alguna". Es decir que ya se establecen los tributos de la República sin siquiera ser República y con esta también la forma en que debía cobrarse.

En adelante las Constituciones de, 1830, 1835, 1852, 1861, 1869, del período Garciano, el ejecutivo gozaba de la facultad de recaudar impuestos de manera anticipada.

Con la Constitución de 1967 el ecuador da un gran paso en lo que se refiere a materia tributaria ya que en esta se consigna un capítulo especial sobre el régimen tributario y se consagra el principio de legalidad, y se dice que los elementos de imposición deben constar por Ley, se constitucionalizan los principios de generalidad e igualdad, se reitera el principio de la capacidad contributiva y se enuncian las proyecciones extra fiscales de imposiciones, se constitucionaliza la jurisdicción contencioso tributaria, así como la jurisdicción contencioso administrativo y por todos estos avances se considera a esta Constitución las más importante en el ámbito tributario hasta la actualidad; manteniéndose el sistema de tributos como una potestad exclusiva por parte del ejecutivo.

Por primera vez en 1907 se implanta en el Ecuador, el proceso coactivo, dentro del Código de Enjuiciamientos en Materia Civil, el cual manifestaba en su art. 1002: "la jurisdicción 
coactiva se ejerce privativamente por los empleados de la Hacienda Pública, a quienes encarga la Ley la Recaudación de la Rentas Fiscales, como ser:

- Tesoreros y Colectores,

- Recaudadores de Rentas y Fondos Destinados a la enseñanza,

- Administradores de los Hospitales, Hospicios, Lazaretos y sitios públicos de caridad,

- Colectores de Rentas Municipales, de cárceles y caminos,

- Colectores eclesiásticos, para la recaudación de la renta que ha sustituido al diezmo.

A partir de esta promulgación el procedimiento coactivo ha ido evolucionando a través de los distintos Códigos Civiles y Tributarios, que se han promulgado para satisfacer las necesidades estatales e institucionales. El actual sistema político del socialismo en íntima relación con el neoconstitucionalismo basa sus proyectos en la recaudación de impuestos como el segundo más grande pilar de sustento económico, por lo que el proceso de recaudación establecido es totalmente parcial, es decir favorece al Estado como desde sus orígenes.

La Décima Novena Constitución de la República del Ecuador, dictada por la Asamblea Nacional constituyente en Montecristi, promulgada en el R. O., el 20 de octubre del 2008, vigente desde la misma fecha, consigna entre los derechos, garantías y deberes de las personas, en particular un capítulo denominado de Los Derechos de Libertad, y al tratar de éstos, en el Art. $75^{\circ}$ expresa lo siguiente:

"Toda persona tiene derecho al acceso GRATUITO a la justicia y a la tutela efectiva, imparcialidad y expedita de sus derechos, intereses, con sujeción a los principio de inmediación y celeridad."

"En ningún caso una persona quedara en INDEFENSIÓN.".

Para entender mejor el debido proceso según el Dr. José García F., es "Hay que señalar que el Debido Proceso quiere una justicia adecuada a la medida de la dignidad humana, pues el proceso se realiza entre seres humanos y no la subordina a nada, de tal modo que si finalmente se condena a alguien, se condena a una persona entera y no a un guiñapo humano como bien dice el Preámbulo del Programa de Justicia para Centro América".

Del Art. $76^{\circ}$ de la Constitución Política de la República del Ecuador confirmando lo anterior, expresa: "Para asegurar el DEBIDO PROCESO, deberán observarse las siguientes garantías básicas...".

Para demostrar que en la acción coactiva existe una vulneración de garantías sobre el debido proceso, hare hincapié en lo que nos dice Luis Cueva Carrión, que define el mismo 
como: "Para entender esta categoría jurídica hay que escribirla al revés: el "proceso debido".

Significa entonces, que el debido proceso es aquel que se debe seguir para asegurar los derechos y las garantías de las partes en un procedimiento jurídico. Es la forma y la manera cómo se debe actuar procesal y jurídicamente.

El debido proceso es un sistema de garantías y de normas jurídicas de carácter sustancial y de grado superior, porque son constitucionales, le señala la debida y correcta actuación al funcionario público, le fija los límites dentro de los que debe actuar y la manera de impartir justicia imparcial, efectiva y oportuna. Es un derecho constitucional que protege a los justiciables para que el órgano estatal actúe de conformidad con la Constitución y la Ley y desarrolle legalmente el procedimiento en base a los más estrictos principios axiológicos y de justicia".

Aplicando esta opinión se puede indicar que el debido proceso tiene por finalidad garantizar el acatamiento de los derechos de las partes involucradas en la sustanciación de un procedimiento jurídico, estableciendo para ello la manera en que se debe actuar de acuerdo con los principios procesales y jurídicos. Al encontrarse el debido proceso en nuestra Constitución de la Republica inmediatamente pasa a ser un derecho constitucional con la finalidad de ejercer de la mejor manera la administración de justicia. En cuanto a la defensa "La defensa en Juicio es el derecho reconocido constitucionalmente de peticionar ante un órgano de justicia, reclamando una resolución o una decisión justa en el litigio. Es también la garantía de ese derecho.

El problema de la defensa en juicio es el problema del individuo a quien se lesiona un derecho subjetivo y debe recurrir a la justicia para reclamar su actuación, en virtud de una garantía institucional que posibilita su reclamación.

El Art. 11, de la Constitución de la República del Ecuador: "Los derechos y garantías establecidos en la Constitución y en los instrumentos internacionales de derechos humanos serán de DIRECTA e INMEDIATAMENTE aplicables por y ante cualquier juez, tribunal o autoridad."

En el inciso primero, explica: "El más alto deber del Estado consiste en respetar y hacer respetar los derechos garantizados en la Constitución"

Y en su cuarto inciso, expone: "El Estado será responsable por detención arbitraria, error judicial, retardo injustificado o inadecuada administración de justicia, violación del derecho a la tutela judicial efectiva, y por las violaciones de los principios y reglas del debido proceso".

El Art. 426 de la Constitución de la República del Ecuador, en su inciso segundo, dispone: "No podrá alegarse falta de Ley o desconocimiento de las nomas para justificar la 
violación de los derechos y garantías establecidos en la Constitución, para desechar la acción interpuesta en su defensa, ni para negar el reconocimiento de tales derechos." y,

El Art. 424 en su inciso segundo expone: "La Constitución y los tratados internacionales de derechos humanos ratificados por el Estado que reconozcan derechos más favorables a los contenidos en la Constitución, prevalecerán sobre cualquier otra norma jurídica o acto del poder público."

El Art. 169 dispone: " EI sistema procesal es un medio para la realización de la justicia. Las normas procesales consagrarán los principios de simplificación, uniformidad, eficacia, inmediación, celeridad y economía procesal, Y HARÁN EFECTIVAS LAS GARANTÍAS DEL DEBIDO PROCESO.

El Art. 424 de la Constitución de la República del Ecuador, en su inciso primero expone: "La Constitución es la norma suprema y prevalece sobre cualquier otra del ordenamiento jurídico.

El Art. 167 de la Constitución de la República del Ecuador, dice: "La potestad de administrar justicia emana del pueblo y se ejerce por los órganos de la Función Judicial y por los demás órganos y funciones establecidos en la Constitución.".

El Art.168 de la Constitución de la República del Ecuador, en el numeral 3 expone: "En virtud de la unidad jurisdiccional, ninguna autoridad de las demás funciones del Estado podrá desempeñar funciones de administración de justicia ordinaria, sin perjuicio de las potestades jurisdiccionales reconocidas por la Constitución.".

Para tener un poco más claro, citare el texto de un tratadista el cual manifiesta que "Dentro del ámbito del que se ocupa el Derecho Administrativo y específicamente en las relaciones que se generan entre la Administración y la Justicia, surge el denominado principio de auto tutela, que podríamos resumirlo como la potestad de la Administración Pública (lato sensu) de exigir por sí misma la ejecución forzosa de los actos de ella emanados (actos administrativos), sin recurrir a los órganos de la Función Judicial”

El Art. 273 de la Constitución de la República del Ecuador, dice: "Las cortes, tribunales, jueces y autoridades administrativas tendrán la obligación de aplicar las normas de la constitución que sean pertinentes, aunque la parte interesada no las invoque expresamente".

El Art. 274 de la Constitución Política de la República del Ecuador, dice: "Cualquier juez o tribunal, en las causas que conozcan, podrá declarar inaplicable, de oficio o a petición de parte, un precepto jurídico contrario a las normas de la Constitución o de los tratados, convenios internacionales, sin perjuicios de fallar sobre el asunto controvertido". Finalmente, el Código de la Función Orgánico Judicial de la República del Ecuador, reformado por la 
Asamblea Nacional constituyente, promulgada en el R. O. 458, el 31 de Octubre del 2008, vigente desde la misma fecha, consigna entre los derechos, garantías y deberes de las personas, y al tratar de éstos los artículos expresan siguiente:

El Art.3 del Código Orgánico de la Función Judicial Ecuatoriano expone: "POLÍTICAS DE JUSTICIA.- Con el fin de garantizar el acceso a la justicia, El debido proceso, la independencia judicial y los demás principios establecidos en la constitución y este Código, dentro de los grandes lineamientos del Plan Nacional de Desarrollo, los órganos de la Función Judicial, en el ámbito de sus competencias, deberán formular políticas administrativas que transformen la Función Judicial para brindar un servicio de calidad de acuerdo a las necesidades de las usuarias y usuarios..."

El Art. 4 del Código Orgánico de la Función Judicial Ecuatoriano, en su inciso primero y segundo manifiesta: PRINCIPIO DE SUPREMACÍA CONSTITUCIONAL. - Las juezas y jueces, las autoridades administrativas y servidoras y servidores de la Función Judicial aplicarán las disposiciones constitucionales, sin necesidad que se encuentren desarrolladas en otras normas de menor jerarquía. En las decisiones no se podrá restringir, menoscabar o inobservar su contenido.

En consecuencia, cualquier jueza o juez, de oficio o a petición de parte, sólo si tiene duda razonable y motivada de que una norma jurídica es contraria a la Constitución o a los instrumentos internacionales de derechos humanos que establezcan derechos más favorables que los reconocidos en la Constitución, suspenderá la tramitación de la causa y remitirá en consulta el expediente a la Corte Constitucional, la que en un plazo no mayor a cuarenta y cinco días resolverá sobre la constitucionalidad de la norma.

Nombramos a su vez cómo Nila Velásquez nos dice: "La Constitución es la norma suprema que rige la vida de una sociedad políticamente organizada, es decir, de un Estado. En ella se definen los principios sobre los cuales se constituye y las características que tendrá su organización. Además, quien no cumplas con la misma poniéndola en primer lugar será sancionado gravemente, pues se violan derechos irrefutables".

Art. 5., del Código Orgánico de la Función Judicial Ecuatoriano, dice: "PRINCIPIO DE APLICABILIDAD DIRECTA E INMEDIATA DE LA NORMA CONSTITUCIONAL. - Las juezas y jueces, las autoridades administrativas y las servidoras y servidores de la Función Judicial, aplicarán directamente las normas constitucionales y las previstas en los instrumentos internacionales de derechos humanos cuando estas últimas sean más favorables a las establecidas en la Constitución, aunque las partes no las invoquen expresamente.

Los derechos consagrados en la Constitución y los instrumentos internacionales de derechos humanos serán de inmediato cumplimiento y aplicación. No podrá alegarse falta 
de ley o desconocimiento de las normas para justificar la vulneración de los derechos y garantías establecidos en la Constitución, para desechar la acción interpuesta en su defensa, o para negar el reconocimiento de tales derechos.

El Art. 9., del Código Orgánico de la Función Judicial Ecuatoriano, expresa: "PRINCIPIO DE IMPARCIALIDAD.- La actuación de las juezas y jueces de la Función Judicial será imparcial, respetando la igualdad ante la ley. En todos los procesos a su cargo, las juezas y jueces deberán resolver siempre las pretensiones y excepciones que hayan deducido los litigantes, sobre la única base de la Constitución, los instrumentos internacionales de derechos humanos, los instrumentos internacionales ratificados por el Estado, la ley y los elementos probatorios aportados por las partes. Con la finalidad de preservar el derecho a la defensa y a la réplica, no se permitirá la realización de audiencias o reuniones privadas o fuera de las etapas procesales correspondientes, entre la jueza o el juez y las partes o sus defensores, salvo que se notifique a la otra parte de conformidad con lo dispuesto en el numeral 14 del artículo 103 de esta Ley."

En este sentido en una sentencia de la Corte Constitucional podríamos tratar: “(...) el juez, en el Estado social de derecho también es un portador de la visión institucional del interés general. El juez, al poner en relación la Constitución -sus principios y sus normas- con la ley y con los hechos, hace uso de una discrecionalidad interpretativa que necesariamente delimita el sentido político de los textos constitucionales. En este sentido la legislación y la decisión judicial son ambas procesos de creación de Derecho.

Ahora bien, el Estado con la finalidad de contar con una vía rápida y eficaz para el cobro de tributos, multas de naturaleza tributaria e intereses (y otras acreencias derivadas de relaciones de Derecho Público) a diferencia del proceso judicial ordinario, ha creado un procedimiento sumarísimo, sencillo en su estructura, conformado por normas procesales de ejecución inmediata, y denominado procedimiento de cobranza coactiva o ejecución coactiva, por medio del cual se obliga a los contribuyentes al pago de la deuda tributaria de inmediato y sin discusión alguna, aunque ésta -la deuda-, no esté acreditada plenamente.

En nuestro país existen dos procedimientos administrativos de ejecución a cargo del Ejecutor Coactivo, en los cuales no es el juez quien ejecuta las medidas coactivas sino un funcionario público.

Estos dos procedimientos que marchan en forma paralela en nuestro ordenamiento jurídico, son, el primero, el regentado por el Decreto Ley $\mathrm{N}^{\circ} 17355$ y sustituido actualmente por la Ley $\mathrm{N}^{\mathrm{o}}$ 26979, para deudas tributarias de los gobiernos locales y deudas no tributarias derivadas de relaciones jurídicas de Derecho público con la Administración Pública; y el segundo, regulado por el Código tributario, para la cobranza de tributos impagos que administra el Gobierno Central. 
Estos procedimientos de cobranza coactiva tienen por objeto la ejecución práctica de la pretensión insatisfecha del fisco y su debido cumplimiento a través de la expropiación forzada de los bienes del deudor, sin entrar a discutir la norma jurídica aplicable ni los hechos que han motivado la deuda, lo que debe hacerse oportunamente en los procedimientos de reclamación y/o apelación; pero cuando se trata de hacer efectiva una deuda tributaria contenida en una orden de pago, ni siquiera los recursos de reclamación o apelación suspenden la cobranza coactiva.

\section{Conclusiones.}

- Una vez realizada la investigación, se ha determinado que existe en el proceso coactivo la violación del derecho a la legítima defensa, por cuanto no permite defenderse sin que previamente se consigne el valor adeudado. Dentro de la investigación, se ha determinado la desigualdad existente dentro de la tramitación del proceso coactivo entre las partes procesales, esto es que el coactivado no se encuentra con la misma tutela efectiva con la que cuenta el Estado.

- En la investigación se ha logrado determinar, la conculcación del principio de Unicidad ya que se tramita los procesos judiciales, fuera de la jurisdicción de los órganos competentes encargados de la Administración de Justicia perteneciente a la Función Judicial.

\section{Recomendaciones}

- Se recomienda que el legislador incorpore en el Art. 968 del Código de Procedimiento Civil la siguiente reforma: "Admisión de excepciones previa consignación y naturaleza de esta.- No se admitirán las excepciones del deudor, sus herederos o fiadores, contra el procedimiento coactivo, si no después de consignada al menos el diez por ciento de la cantidad a que asciende la deuda, sus intereses y costas previa liquidación aprobada. La consignación se hará con arreglo al artículo 196 de la Ley Orgánica de Administración Financiera y Control, a órdenes del recaudador con estricta observación de lo dispuesto en el inciso precedente."

- Que se respete el debido proceso cuyo derecho es protegido, tutelado y garantizado constitucionalmente por el Estado, siendo incongruente ya que el mismo es parte procesal Arts. 75 -76.

- Se recomienda al Consejo de la Judicatura, crear juzgados de jurisdicción coactiva respetando lo dispuesto en el Art. 168. 3 al hablar del principio de Unidad Jurisdiccional.

\section{Referencias Bibliográficas}

ALEXY ROBERTH (2008) Teoría de los Derechos Fundamentales, trad. Por Carlos Bernal Pulido, Madrid, Centro de Estudios Políticos y Constitucionales. 
ALEXY. ROBERTH (2007) Teoría de la Argumentación Jurídica: Teoría del discurso racional como teoría de la fundamentación jurídica, Madrid-España, Segunda Edición. Centro de Estudios Constitucionales.

ÁVILA RAMIRO, GRIJALVA AGUSTIIN Y MARTÍNEZ RUBÉN (2008) Desafíos Constitucionales, La Constitución ecuatoriana del 2008 en perspectiva, Quito-Ecuador, Serie Justicia y Derechos Humanos Neoconstitucionalismo y Sociedad, 2008

CÓDIGO DE PROCEDIMIENTO CIVIL, Editorial Corporación de Estudios y Publicaciones, Quito-Ecuador, 2013.

CÓDIGO ORGÁNICO DE LA FUNCIÓN JUDICIAL, Editorial Corporación de Estudios y Publicaciones, Quito- Ecuador, 2013.

CONSTITUCIÓN DE LA REPÚBLICA DEL ECUADOR, Editorial Corporación de Estudios y Publicaciones, Quito-Ecuador, 2013.

CUEVA CARRIÓN, Luis (2013) El Debido Proceso, Segunda Edición Actualizada y Ampliada, Ediciones Cueva Camón, Quito-Ecuador, pág. 81.CÁRDENAS

DUGUIT, LÉON (2013) Soberanía y Libertad. Lecciones dadas en la Universidad de Columbia (New York, 1920-1921) (edición y "Estudio preliminar" de José Luis Monereo, Granada, Comares), 159 págs.

ESCOBAR VÉLEZ, EDGAR GUILLERMO (2003) "El proceso de Jurisdicción Coactiva". Medellín, Señal Editora.

FRANCISCO GUERRERO CELI (2007) INTRODUCCIÓN A LA ACCIÓN COACTIVA. Publicación en el 2007, pág. 1 párrafo 1.

FRANKLIN RUILOVA ARCE (2008) Inobservancia del debido proceso en los procedimientos coactivos.

RIOSECO, Raúl (2006) La Presunción de Inocencia, Segunda Edición, Editorial Porrúa S.A., México D.F., pág. 23.

SILVA ARMANDO (2007) El Derecho a la Defensa en el Ámbito Procesal, Editorial Temis, Bogotá-Colombia, pág. 21.

VELASQUEZ NILA, La Supremacía de la Constitución, Diario El Universo, sábado 10 de agosto, 2013. 


\section{PARA CITAR EL ARTÍCULO INDEXADO.}

Loza Torres, A., Colcha Ortiz, R., Carrera Silva, K., \& Moreno Albuja, M. D. C. (2019). Violación del derecho a la defensa de las personas y el debido proceso en los juicios de jurisdicción coactiva en el art. 968 del código de procedimiento civil. Visionario Digital, 3(3), 179-191. https://doi.org/10.33262/visionariodigital.v3i3.668

\section{\Ciencia}

El artículo que se publica es de exclusiva responsabilidad de los autores y no necesariamente reflejan el pensamiento de la Revista Visionario Digital.

El artículo queda en propiedad de la revista y, por tanto, su publicación parcial y/o total en otro medio tiene que ser autorizado por el director de la Revista Visionario Digital.
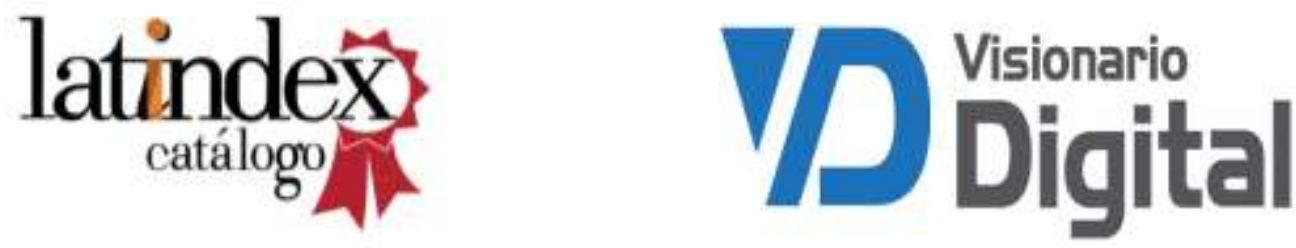